[0212-7199 (2005) 22: 5; pp 231-234] ANALES DE MEDICINA INTERNA Copyright (C) 2005 ARAN EDICIONES, S.L.

An. Med. INTERNA (Madrid) Vol. 22, N. ${ }^{\circ}$ 5, pp. 231-234, 2005

\title{
Enfermedad de Whipple. Dos nuevos casos de una enfermedad infradiagnosticada
}

\author{
A. M. GARCÍA BERNÁRDEZ, A. I. GARCÍA DÍEZ, C. C. ÁLVAREZ CUESTA, \\ M. GALLEGO VILLALOBOS, E. VALLINA ÁLVAREZ, J. M. ARRIBAS CASTRILLO \\ Servicio de Medicina Interna I. Hospital Central de Asturias. Oviedo
}

WHIPPLE'S DISEASE. TWO NEW CASES OF AN UNDERDIAGNOSED DISEASE

\section{RESUMEN}

La enfermedad de Whipple, también conocida como lipodistrofia intestinal, es un proceso infeccioso, multisistémico y poco frecuente, causado por la bacteria Tropheryma whippelii.

El diagnóstico precoz es fundamental porque esta enfermedad es potencialmente letal, pero responde espectacularmente al tratamiento antibiótico.

El diagnóstico se confirma con la reacción en cadena de la polimerasa (PCR) que también es útil para monitorizar la respuesta al tratamiento

Actualmente el tratamiento recomendado consiste en la administración de cotrimoxazol oral dos veces al día durante un año. Cuando hay afectación del SNC se aconseja iniciar el tratamiento con la administración intramuscular de 1 gramo de estreptomicina asociado a 1,2 $\mathrm{MU}$ de bencil penicilina (penicilina $\mathrm{G}$ ) de forma diaria durante 14 días.

PALABRAS CLAVE: Enfermedad de Whipple. Tropheryma whippelii.

\begin{abstract}
Whipple's disease is a rare systemic infectious disease caused by the bacterium Tropheryma whippelii.

Early diagnosis is essential. Whipple's disease is potentially fatal but responds dramatically to antibiotic treatment.

The diagnosis is confirmed by means of polymerase chain reaction $(P C R)$ technology. This analysis may be useful for monitoring the efficacy of therapy.

The recommended treatment al present is administration of cotrimoxazole twice daily for one year. When CNS involvement occurs, it is recommended initial treatment with daily parenteral administration of streptomycin $1 \mathrm{~g}$ and 1,2 million units of benzyl penicillin (Penicillin $G$ ) over a period of 14 days.
\end{abstract}

KEY WORDS: Whipple's disease. Tropheryma whippelii.

García Bernárdez AM, García Díez, AI, Álvarez Cuesta CC, Gallego Villalobos M, Vallina Álvarez E, Arribas Castrillo JM. Enfermedad de Whipple. Dos nuevos casos de una enfermedad infradiagnosticada. An Med Interna (Madrid) 2005; 22: 231-234.

\section{INTRODUCCIÓN}

La enfermedad de Whipple fue descrita por George Whipple en 1907 (1). Desde entonces se han descrito menos de 10 casos al año en la bibliografía mundial (2). El espectro del cuadro clínico de esta enfermedad es muy amplio y diverso lo que en ocasiones dificulta y retrasa el diagnóstico.

Presentamos dos nuevos casos de esta infrecuente entidad diagnosticados en nuestro hospital. El primer caso se trata de un varón con artralgias de varios años de evolución que consulta por diarrea y pérdida de peso. El segundo caso es el de una mujer con múltiples episodios de anemia y fallo cardíaco secundario que ingresa para estudio de un síndrome general.

\section{CASOS APORTADOS}

Caso 1: Varón de 70 años que consultó por diarrea y pérdida de peso. Como antecedentes de interés presentaba hipertensión arterial y fibrilación auricular. Siete años antes se le había hecho un recambio valvular aórtico por insuficiencia severa. Presentaba artralgias de varios años de evolución que habían sido etiquetadas de poliartritis seronegativa. El paciente acudió a Consultas Externas de Medicina Interna por un cuadro de un mes de evolución de diarrea líquida con moco y pérdida de $10 \mathrm{~kg}$ de peso. No refería haber termometrado fiebre.

En la exploración física destacaba una tensión arterial de 70/40 $\mathrm{mm}$ de $\mathrm{Hg}$. Presentaba hábito asténico. No existía focalidad neurológica. No se palpaban adenopatías. La auscultación cardíaca era arrítmica con "click" valvular. La auscultación pulmonar era normal. 
El abdomen era blando y depresible con dolor a la palpación en epigastrio y peristalsis aumentada. Se realizaron distintos estudios complementarios entre los que destacamos: Hemograma: Hb: 8,6 g/dL. VCM: 81 fL. HCM: 26 pg. Leucocitos y plaquetas: dentro de límites normales. VSG: $76 \mathrm{~mm} / 1^{\mathrm{a}}$ hora. Bioquímica: colesterol: $79 \mathrm{mg} / \mathrm{dl}$. Proteínas totales: 5,7 g/dl. Albúmina: 2,4 g/dl. TSH, cortisol am, cortisol pm y ACTH: Dentro de límites normales. Anticuerpos antigliadina, antiendomisio y antitransglutaminasa: Negativos. Coprocultivo: flora bacteriana habitual. No se observaron huevos ni quistes de parásitos intestinales. Aumento de principios inmediatos en heces. TC abdominal: adenopatías retroperitoneales múltiples. Gastroscopia: gastritis crónica. Linfangiectasia duodenal. Se realizaron varias biopsias duodenales. El estudio histopatológico con microscopía óptica mostró un ensanchamiento y aplanamiento de las vellosidades intestinales, así como la lámina propia de la mucosa intestinal masivamente ocupada y expandida por una proliferación difusa de elementos histiocitarios (Fig. 1). La histoquímica mostró una técnica de PAS intensamente positiva en las células histiocitarias con un patrón granular.

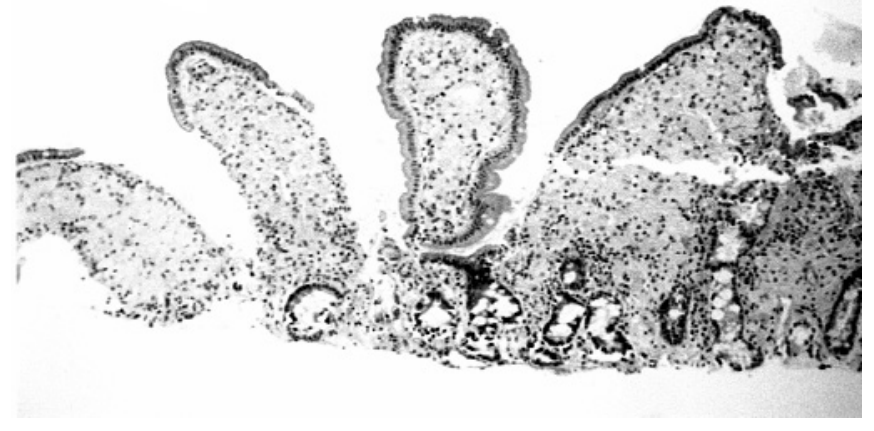

Fig. 1. Ensanchamiento y aplanamiento de las vellosidades intestinales (HE 200x).

El paciente fue diagnosticado según los datos clínicos y los resultados de las pruebas complementarias mencionadas de enfermedad de Whipple, iniciándose el tratamiento antibiótico con cotrimoxazol oral $(160 / 800 \mathrm{mg})$ dos veces al día y ácido fólico; tras 9 meses de tratamiento el paciente está asintomático, sin diarrea y ha ganado $8 \mathrm{~kg}$ de peso.

Caso 2: Mujer de 73 años con antecedentes de síndrome depresivo, artrosis, osteoporosis, divertículos en sigma y varios ingresos por anemia y fallo cardíaco secundario. Se había realizado un amplio estudio, incluyendo endoscopias digestivas, siendo todos los resultados normales. Ingresó de nuevo por astenia y pérdida de $14 \mathrm{~kg}$ en los últimos 10 meses. No refería diarrea, artralgias ni otra clínica asociada. No había termometrado fiebre.

En el examen físico presentaba unas cifras de tensión arterial de 110/70 mm de Hg y una marcada palidez cutáneo mucosa. La auscultación cardíaca era rítmica a 100 latidos por minuto y la auscultación pulmonar mostraba algún crepitante fino en las bases. Dentro de las pruebas complementarias realizadas destacamos: hemograma: Hb: 7,8 g/L. VCM: 81 fL. Plaquetas y leucocitos: dentro de límites normales. VSG: $112 \mathrm{~mm}$ de Hg bioquímica: proteínas totales: $6,3 \mathrm{~g} / \mathrm{dl}$. Albúmina: 2,5 g/dl. Anticuerpos antigliadina, antiendomisio y antitransglutaminasa: Negativos. Sangre ocul- ta en heces ( 2 determinaciones): Positiva. Principios inmediatos en heces: Normales. Coprocultivo: Flora habitual. TSH, cortisol y ACTH: Normales. Gastroscopia: Hallazgos compatibles con gastritis crónica. En el duodeno se observaron múltiples zonas blanquecinas y engrosamiento de los pliegues con aspecto en mosaico. Se tomaron biopsias y el estudio histopatológico mostró unas vellosidades gruesas debido a una colección de histiocitos de citoplasma finamente granular localizados en la lámina propia con tinción de PAS positiva. Se realiza TC abdominal (Fig. 2) donde se objetivaron múltiples adenopatías retroperitoneales en rango patológico situadas fundamentalmente en la raíz de mesenterio. Se solicitó consulta al Servicio de Cirugía General para realizar laparotomía.

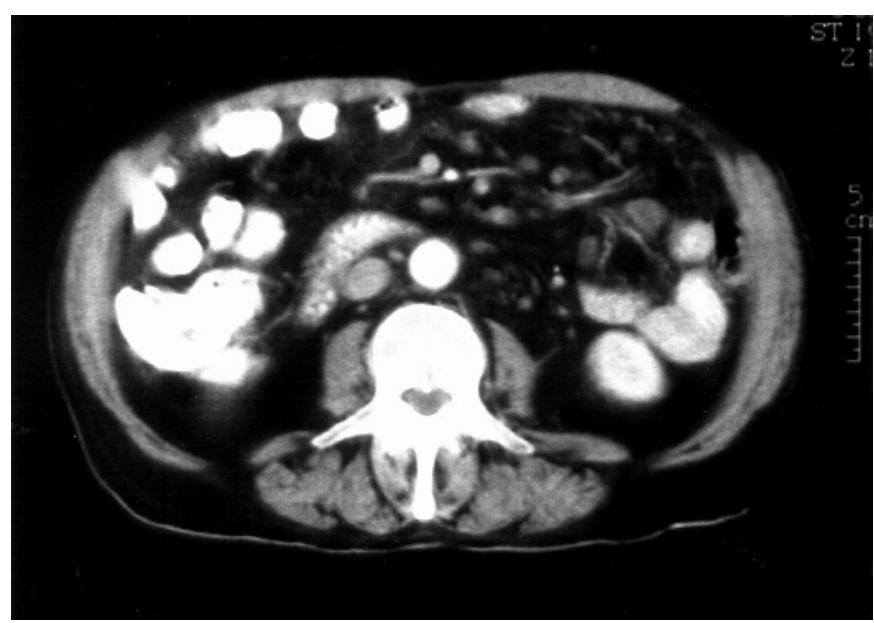

Fig. 2. TC abdominal: múltiples adenopatías retroperitoneales, sobre todo en la raíz del mesenterio.

Se realizaron biopsias duodenales y ganglionares intraoperatorias y se solicitó PCR en el material de dichas biopsias. La confirmación mediante esta técnica de la presencia de infección por Tropheryma whippelii nos permitió en este caso realizar el diagnóstico de la enfermedad.

Se inició tratamiento antibiótico con cotrimoxazol y suplementos de ácido fólico. Actualmente el paciente se encuentra en el tercer mes de tratamiento, ha empezado ha recuperar peso y mantiene cifras de hemoglobina entorno a $11 \mathrm{~g}$.

\section{DISCUSIÓN}

La enfermedad de Whipple es un proceso infeccioso causado por la bacteria Tropheryma whippelli. La primera evidencia de que la enfermedad tenía un origen infeccioso se obtuvo en 1952, cuando Paulley publica los primeros resultados de éxito terapeútico tras el tratamiento de la enfermedad con cloranfenicol (3). En 1961 se demostró que la bacteria implicada en la enfermedad de Whipple es un bacilo con forma de hoz que se tiñe con las tinciones de PAS, Gram, y Giemsa. El microorganismo causal se caracterizó molecularmente en 1991 mediante la reacción en cadena de la polimerasa y en el año 2000 se ha logrado cultivar en células HLE (línea celular de fibroblastos humanos) (4).

Predomina en varones de raza blanca entre los 40-50 años (5-7). No se han descrito factores de riesgo ocupacio- 
nales. No es una enfermedad familiar pero el HLA-B27 es más frecuente en estos pacientes que en la población general (8).

El espectro de síntomas clínicos de esta enfermedad es muy variado y en ocasiones inespecífico, lo que puede dificultar su diagnóstico. Los síntomas clásicos son: diarrea, malabsorción y pérdida de peso. Pueden aparecer trastornos oculares como retinitis, uveitis, neuritis retrobulbar y papiledema $(1,9)$. El 40\% de los pacientes presentan hiperpigmentación cutánea en áreas fotoexpuestas (10). En ocasiones el proceso debuta como un cuadro de artralgias o artritis de carácter migratorio de años de evolución ( como sucedió con nuestro primer paciente). El 10\% de los pacientes presentan síntomas neurológicos. La tríada demencia, oftalmoplejía y mioclonías se describe con frecuencia (11). La miorritmia oculomasticatoria, que es una oscilación ocular pendular convergente-divergente lenta $(1 \mathrm{~Hz})$ asociada a movimientos síncronos de la boca y otras partes del cuerpo, es un síntoma infrecuente pero se considera patognomónico de la enfermedad $(7,11)$. También están descritas las manifestaciones cardiovasculares, como son la endocarditis, miocarditis y pericarditis (5). Aunque las alteraciones cardíacas son un hallazgo frecuente en la autopsia, es infrecuente que tengan repercusión clínica.

Esta enfermedad puede provocar afectación renal en forma de nefritis crónica intersticial, glomerulonefritis o nefropatía Ig A, y otros síntomas y signos poco específicos como disnea, tos crónica y fiebre.

En lo que que se refiere al diagnóstico, la endoscopia oral con biopsia duodenal probablemente sea la exploración más útil y rentable, debido a que la afectación intestinal comienza en la primera porción duodenal, lugar de fácil acceso al endoscopio (12). Sin embargo, la endoscopia puede ser normal hasta en un $30 \%$ de los casos (7).

En la duodenoscopia realizada a los pacientes con enfermedad de Whipple se observan unas imágenes muy características consistentes en un patrón miliar con un punteado blanquecino-amarillento, que puede confluir formando máculas blanquecinas en la mucosa duodenal, entre la cual se sitúan tractos rojizo-hemorrágicos, adoptando un aspecto en "alfombrilla de pelos" $(1,13)$.

Los datos anatomopatológicos más característicos se observan por medio del microscopio óptico . Lo más llamativo es una infiltración extensa de la lámina propia del intestino delgado por macrófagos grandes, cuyo citoplasma está lleno de gránulos glucoproteicos que captan la tinción del PAS. El acúmulo de estos macrófagos distorsiona la arquitectura vellositaria. Asimismo, puede existir un incremento del número de leucocitos polimorfonucleares en la lámina propia. Estos hallazgos son sugestivos de enfermedad de Whipple pero no patognomónicos. Pueden aparecer también macrófagos PAS + en la biopsia intestinal de pacientes con tuberculosis, sarcoidosis, beriliosis, infección por MAI, histoplasmosis diseminada, macroglobulinemia y otras $(1,5,7,9)$. Con el microscopio electrónico se ven bacterias intra y extracelulares (13). El material glucoproteico PAS + que se ve en el interior de los macrófagos, son restos de la pared celular de estas bacterias.

Actualmente las técnicas moleculares que utilizan los métodos de amplificación genética mediante la reacción en cadena de la polimerasa o PCR, permiten identificar el bacilo en tejidos (biopsia duodenal), en fluidos orgánicos (LCR) o en células mononucleares de sangre periférica. La PCR es una importante herramienta diagnóstica para muchas enfermedades de origen bacteriano y la enfermedad de Whipple es un ejemplo más (2).

Otras técnicas de imagen pueden aportar datos complementarios que ayudan al diagnóstico. En el tránsito intestinal aparecen signos indirectos de malabsorción y engrosamiento de los pliegues $(1,13)$.

La tomografía axial computarizada abdominal pone de manifiesto adenopatías retroperitoneales múltiples (1), como en nuestros dos pacientes.

El tratamiento debe realizarse usando antibióticos que atraviesen la barrera hematoencefálica para evitar las recidivas neurológicas que son las más frecuentes (11) y habitualmente resistentes a la terapia $(1,11,13)$.

El tratamiento recomendado actualmente (14) consiste en la administración de trimetropim-sulfametoxazol 160/800 mgr cada 12 horas vía oral durante al menos un año. En los casos más graves o con afectación neurológica se aconseja iniciar el tratamiento con la administración por vía intramuscular de 1,2 MU de bencilpenicilina (penicilina G) asociado a 1 gramo de estreptomicina diaria, durante 14 días.

Los pacientes mejoran clínicamente a las 3 semanas de instaurarse el tratamiento antibiótico. La desaparición de algunos datos clínicos como la fiebre, las adenopatías, la hiperpigmentación cutánea o la ganancia de peso, pueden servir de indicadores de la buena evolución de la enfermedad.

Los macrófagos PAS + disminuyen lentamente y pueden observarse en la biopsia intestinal hasta un año después de haber instaurado un tratamiento antibiótico correcto $(1,2,15)$. Por lo tanto su presencia no deber usarse como indicador de la eficacia del mismo.

El parámetro más importante para vigilar y predecir una recurrencia, es la presencia de bacilos en la biopsia intestinal. Tras nueve semanas de tratamiento antibiótico los bacilos deben haber desaparecido de la lámina propia. Con frecuencia, la reaparición de éstos anuncia una recaída clínica después de suspender los antibióticos $(1,2)$.

La PCR también es útil para monitorizar la respuesta al tratamiento $(14,16)$. Generalmente se demuestra una ausencia de amplificación a los dos meses de haberlo iniciado. Sin embargo una limitación de esta técnica es que su positividad una vez instaurado el tratamiento, puede deberse tanto a la persistencia de la infección como a la persistencia del ADN de los bacilos ya muertos.

Algunos autores aconsejan realizar PCR en el LCR antes y después del tratamiento, dado que puede haber afectación neurológica aún en ausencia de clínica.

El $90 \%$ de los pacientes evolucionan de forma favorable con el tratamiento antibiótico (7). Para evitar las recaídas, que ocurren en el $20 \%$ de los casos, el tratamiento debe ser prolongado (2). La mayoría de los autores aconsejan mantenerlo durante un año, incluso algunos lo recomiendan de forma indefinida. Otros aconsejan mantenerlo hasta que la PCR del LCR se negativice.

Con estos dos casos pretendemos poner de manifiesto el cuadro clínico tan variado que puede presentar esta enfermedad, recordando que en ocasiones la clínica extradigestiva puede preceder en años a los síntomas clásicos (diarrea, malabsorción y pérdida de peso) dificultando y retrasando el diagnóstico. 


\section{Bibliografía}

1. Gisbert JP, Martín Scapa MA, Álvarez Baleriola I, Moeira Vicente V, Hernández Ranz F. Enfermedad de Whipple: una entidad a tener en cuenta. Rev Clin Esp 1995; 195: 627-32.

2. Pérez Gracia MT, Rodríguez Iglesias MA. Enfermedad de Whipple. Med Clin (Barc) 1997; 109: 677-83.

3. Paulley JW. A case of Whipple's disease. Gastroenterology 1952; 22: 128-33.

4. Raoult D, Birg M, La Scola B, Fournier P, Enea M, Lepidi H, et al. Cultivation of the bacillus of Whipple's disease. N Engl J Med 2000; 342: 620-25.

5. Oteo JA, Blanco JR. Enfermedad de Whipple. Enferm Infec Microbiol Clin 2000; 18: 428-30.

6. Jirout Casillas F, Ballina García FJ, Fernández Sánchez JA, Queiro Silva R, Ordás Calvo C, Rodríguez Pérez A. Manifestaciones atípicas de la enfermedad de Whipple. An Med Interna (Madrid) 2001; 18: 24-63

7. Reyes Martínez C, Cordero Fernández C, Torronteras Santiago R, Reina Campos FR, Márquez Galán JL, Sánchez Agüera M. Enfermedad de Whipple: presentación de los casos diagnosticados en nuestro hospital. Rev Esp Enferm Dig 2003; 95:143-48.
8. Ponte C, Soriano F. Enfermedad de Whipple: más cerca de la identidad del agente etiológico. Rev Clin Esp 1995; 195: 598-99.

9. Case Records of the Massachusetts Hospital (Case 37-1997). N Engl J Med 1997; 337: 1612-9.

10. Chandhini R, Boynton RF. Whipple's disease. Gastroenterology 1998; 27: 683-95.

11. Alba D, Molina F, Vázquez J. Manifestaciones neurológicas de la enfermedad de Whipple. An Med Interna (Madrid) 1995; 12: 508-12.

12. Domínguez F, Saus C, Boixeda D. Enfermedad de Whipple: aspectos endoscópicos y utilidad de la biopsia endoscópica en el diagnóstico y seguimiento. Gastroenterol Hepatol 1989; 12: 33-5.

13. Encinas Sotillos A, Cano López JM, Cano Jiménez A, Muro González J. Enfermedad de Whipple. Rev Esp Enferm Digest 1988; 73: 521-6.

14. Zúñiga A, Bernet L, Bustamante M, Cano R. Enfermedad de Whipple diagnosticada por técnica de reacción en cadena de la polimerasa. Med Clin (Barc) 2004; 122: 115-9.

15. Ratnaike RN. Whipple's disease. Postgrad Med 2000; 76: 760-66.

16. Maiwald M, Relman DA. Whipple's Disease and Tropheryma whippelii: Secrets Slowly Revealed. Clin Infect Dis 2001; 32: 457-63. 